\title{
Short-term effects of prolactin on prostatic function in rats with lisuride-induced hypoprolactinaemia
}

\author{
H. Rui*, E. Haug†, B. Mevågł, Y. Thomassen§ and K. Purvis* \\ *Institute of Pathology, $\ddagger$ Institute of Forensic Medicine, Rikshospitalet, and \\ $\dagger$ Hormone Laboratory, Aker Hospital and §Institute of Occupational Health, Oslo, Norway
}

\begin{abstract}
Summary. The effects of a single injection of ovine prolactin on prostatic function were monitored in intact, intact androgenized and castrated-androgenized rats rendered hypoprolactinaemic after 7 days of treatment with a potent dopamine agonist, lisuride. Hypoprolactinaemia was associated with reductions in ventral prostate weight, polyamine levels, lateral lobe zinc and the concentration of the ventral prostate protein prostatein, but an elevation in the level of cytosolic oestradiol binding. Whether these differences attained statistical significance depended on whether the animals were intact, intact-androgenized or castrated-androgenized. With the exception of ventral prostate weight and lateral lobe zinc concentrations, a single injection of prolactin restored or reversed these changes towards control levels within $12 \mathrm{~h}$, which could not be explained by an indirect effect of the hormone on adrenal or testicular function. No effects of lisuride or prolactin were observed with regard to the content of fructose in the coagulating gland or in the degree of prolactin binding to prostatic membranes.
\end{abstract}

\section{Introduction}

There has accumulated convincing evidence that prolactin is necessary for the maintenance of accessory sex gland function. With regard to the rat prostate, prolactin has been reported to have positive effects on weight (Grayhack, 1963; Bartke \& Lloyd, 1970; Negro-Vilar, Saad \& McCann, 1977), nucleic acid levels (Thomas \& Manandhar, 1975; Thomas, Manandhar, Keenan, Edwards \& Klase, 1976; Prins \& Lee, 1983), cell proliferation (Baker, Worgut, Santen, Jefferson \& Bardin, 1977; McKeehan, Adams \& Rosser, 1984), protein synthesis (Thomas \& Manandhar, 1975), zinc uptake (Weinstein \& Rosoff, 1972; Moger \& Geschwind, 1972), citric acid concentration (Grayhack, 1963; Grayhack \& Lebowitz, 1967; Walvoord, Resnick \& Grayhack, 1976; Slaunwhite \& Sharma, 1977) and the activity of acid phosphatase (Ghosh, Chatterjee \& Ghosh, 1983). The above effects are in accordance with the presence of specific prolactin binding sites in the rat prostate (Aragona \& Friesen, 1975; Hanlin \& Yount, 1975; Thompson, Johnson \& Brooks, 1982).

Work in this area has been facilitated by the use of dopamine agonists such as bromocriptine, which can specifically reduce circulating prolactin concentrations (Flückiger, 1976). The present work examined the short-term effects of prolactin withdrawal in the adult male rat, using another ergot derivative, lisuride, which is at least as potent as bromocriptine (Gräf, Neumann \& Horowski, 1976), and water-soluble and therefore easier to administer. In addition to some of the conventional response indicators such as organ weight, zinc and fructose content, we also monitored oestrogen binding and prolactin binding, the levels of prostatein, a specific secretory protein from the ventral prostate (Lea, Petrusz \& French, 1979), and the polyamines spermidine and spermine, and their diamine precursor putrescine.

Purvis, Clausen, Olsen, Haug \& Hansson (1979) have indicated that a reduction in circulating prolactin has a negative effect on Leydig cell function in the rat, and inconsistent effects of prolactin suppression on circulating testosterone have been reported (Harper, Danutra, Chandler 
\& Griffiths, 1976; Bartke, 1980). Experiments were therefore carried out using intact, intact androgenized and castrated-androgenized rats on three separate occasions. In addition to lisuride treatment, a subgroup of animals in each experiment also received a single dose of prolactin $12 \mathrm{~h}$ before being killed to examine whether any of the changes induced by prolactin withdrawal could be rapidly reversed.

\section{Materials and Methods}

Adult male Sprague-Dawley rats (150-180 days) were used in all experiments.

Effects of lisuride on circadian variations in hormone levels. This experiment was carried out to study the short-term effects of the dopamine agonist on circulating plasma hormones during the day to assess its efficacy in reducing plasma prolactin without disturbing other hormones. Fifty intact rats were randomly allocated to groups of 5 . Half of the animals were treated with $25 \mu \mathrm{g}$ lisuride (lisuride hydrogen maleate: Schering AG, Berlin, FRG) dissolved in $0.9 \%(\mathrm{w} / \mathrm{v}) \mathrm{NaCl}$ $(0 \cdot 1 \mathrm{ml})$ twice a day $(09: 00$ and 21:00 h), whereas controls received saline only. This dose of lisuride had been earlier judged to be the most effective concentration for inhibiting prolactin without causing undesirable behavioural effects (data not shown). On the 4th day of treatment rats were killed at 3, 6, 9 and $12 \mathrm{~h}$ after the morning injection. Rats killed at time zero did not receive this final injection. Trunk blood from these animals was collected and the plasma concentrations of prolactin, LH, testosterone and corticosterone were measured.

Effects of lisuride and prolactin on the prostate. Rats were allocated to 3 groups of 8 animals. Two of the groups were injected subcutaneously with $25 \mu \mathrm{g}$ lisuride twice a day for 7 days, whereas the control group received saline. Towards the end of the study one of the lisuride-treated groups received $75 \mu \mathrm{g}$ (2.3 i.u.) ovine prolactin (Sigma Chemical Co., St Louis, MO, U.S.A.) in 0.2 ml phosphate-buffered saline, $\mathrm{pH} \mathrm{7.4,} \mathrm{s.c.)} \mathrm{concomitant} \mathrm{with} \mathrm{the} \mathrm{last} \mathrm{lisuride} \mathrm{injection} 12 \mathrm{~h}$ before autopsy. This experiment, which was initially carried out using intact rats, was repeated with intact animals in which circulating androgen was kept artificially at a constant level by daily injection of $100 \mu \mathrm{g}$ testosterone propionate (in $0.1 \mathrm{ml}$ peanut oil, i.m.) which was initiated concomitant with the first lisuride injection. A third study was also carried out with castrated rats that were given the same amount of androgen. The castration was performed via the scrotal route, and androgen replacement and lisuride treatment were initiated the following day. The animals were killed by decapitation, and trunk blood was collected in heparinized tubes. Plasma was obtained by centrifugation at $1500 \mathrm{~g}$ and $4^{\circ} \mathrm{C}$ for $10 \mathrm{~min}$ and stored at $-70^{\circ} \mathrm{C}$ until used for assay of prolactin, $\mathrm{LH}$ and testosterone concentrations. Ventral lobes and coagulating glands were removed, and tissue from the lateral lobes was dissected out and frozen immediately in tubes in a solid $\mathrm{CO}_{2}$-ethanol bath. Tissues were then transferred to $-70^{\circ} \mathrm{C}$ until the day of assay. Oestradiol and prolactin binding were in all cases determined within 3 days. Seminal vesicles were ligated before removal, and the weight of the secretion was obtained as the difference between total organ weight and the weight after extrusion of the contents onto absorbent paper.

Assay of plasma hormones. LH, prolactin and testosterone were determined using radioimmunoassay procedures described elsewhere (Purvis, Illius \& Haynes, 1974; Haug \& Gautvik, 1976; Purvis, Haug, Clausen, Naess \& Hansson, 1977). The sensitivities and the within-assay coefficients of variation were $200 \mathrm{pg}$ and $<7 \%$ for $\mathrm{LH}$ and prolactin, and $12.5 \mathrm{pg}$ and $<6 \%$ for testosterone.

Corticosterone was measured by a competitive protein-binding assay also described earlier (Purvis, Calandra \& Hansson, 1977). Assay sensitivity was $200 \mathrm{pg}$ and the within-assay coefficient of variation was always $<10 \%$. 
Assay of prolactin binding. The details of the method have been published previously (Charreau et al., 1977); the method is based on the incubation of individual membrane preparations with iodinated human prolactin at room temperature for $16-18 \mathrm{~h}$ in the presence or absence of excess unlabelled hormone. In the experiment using intact androgenized rats, the binding was measured on pools of tissues. All determinations were carried out in triplicate, and the within-assay coefficient of variation was $<5 \%$.

Assay of cytosolic oestrogen binding. Studies on the prostatic oestrogen receptor and validation of the receptor assays have been reported previously (Ginsburg, Jung-Testas \& Baulieu, 1980; Jung-Testas et al., 1981; Purvis, Mørkås, Rui \& Attramadal, 1985). Tissue was homogenized in 5 volumes of Tris- $\mathrm{HCl}$ buffer (10 mM, pH 7.4) containing $1 \mathrm{mm-EDTA,} 1 \mathrm{~mm}$-2-mercaptoethanol and $250 \mathrm{~mm}$-sucrose. The homogenate was centrifuged at $105000 \mathrm{~g}$ for $1 \mathrm{~h}$ at $4{ }^{\circ} \mathrm{C}$ and aliquants $(200 \mu \mathrm{l})$ of the supernatant were incubated on ice for $16-18 \mathrm{~h}$ in the presence of a 40 -fold excess of non-radioactive $5 \alpha$-dihydrotestosterone. Parallel aliquants were incubated with a 100 -fold excess of unlabelled oestradiol to evaluate the extent of non-specific binding. The total incubation volume was $300 \mu \mathrm{l}$. Unbound hormone was removed by incubation on ice for $10 \mathrm{~min}$ with dextran-charcoal followed by centrifugation. Scatchard analysis was carried out using the same procedure as above but after incubating with various amounts of $\left[{ }^{3} \mathrm{H}\right]$ oestradiol $(0 \cdot 2-3 \cdot 0 \mathrm{nM})$. Non-specific binding was estimated at each point of the Scatchard plot and binding was expressed as $\mathrm{fmol}$ bound/mg protein. The within-assay coefficient of variation was $<3 \%$.

Assay of prostatein. Ventral lobe prostatein content was determined by rocket electrophoresis as described by Lea et al. (1979). Aliquants $(3-20 \mu \mathrm{l})$ of individual cytosols $(105000 \mathrm{~g}$ for $1 \mathrm{~h}$, diluted 1:500) were run on polyacrylamide gels. In the experiment using intact androgenized rats, the assay was carried out on pooled cytosols. Duplicate or triplicate determinations were carried out, and results were expressed in arbitrary units in the form of $\mathrm{cm}$ rocket height. The within-assay coefficient of variation was $<8 \%$.

Assay of zinc. Lateral lobe tissue was homogenized in 20 volumes of Tris- $\mathrm{HCl}$ buffer, and deproteinized in 1 volume of $10 \%$ trichloroacetic acid (TCA). A Perkin-Elmer model 5000 atomic absorption spectrophotometer equipped with a Zn-EDL lamp and the microcup flame atomization technique were used. Buffer-TCA blanks were assayed in parallel.

Assay of fructose. Coagulating gland cytosols (105000 $\mathrm{g}$ supernatants) were deproteinized in 1 volume of $10 \% \mathrm{TCA}$, and fructose was determined according to the procedure of Ricterich (1969), which is based on the colorimetric determination of a yellow reaction product resulting from fructose and anthrone (Sigma Chemical Co.). The within-assay coefficient of variation was $<10 \%$. Fructose measurement was not performed in the last experiment with castrated rats, because the previous experiments had failed to reveal any effect of prolactin on this measure.

Assay of polyamines. The polyamines spermidine and spermine and their diamine precursor, putrescine, were determined by a high-pressure liquid chromatography technique (Laboratory Data Control, Milton Roy Co., Riviera Branch, FL, U.S.A.), using a procedure which was a slight modification of that of Seiler \& Knödgen (1978). Briefly, $100 \mu \mathrm{l}$ samples of cytosols $(20000 \mathrm{~g}$ for $30 \mathrm{~min}$ ) from ventral lobe tissue were mixed with $300 \mu \mathrm{l}$ of internal standard solution $(1,6-$ diaminohexane, $25 \mathrm{nmol}$ in water) and deproteinized with $400 \mu \mathrm{l} 0.4 \mathrm{M}$-perchloric acid (PCA) on ice for $20 \mathrm{~min}$, followed by centrifugation at $2000 \mathrm{~g}$ for $30 \mathrm{~min}$. A sample $(100 \mu \mathrm{l})$ of the supernatant was diluted with $100 \mu \mathrm{l}$ water and mixed with $100 \mathrm{mg} \mathrm{NaHCO}$ and $400 \mu \mathrm{l}$ dansyl chloride (Sigma Chemical Co.; $0.11 \mathrm{~m}$ in acetone). The reaction mixture was allowed to stand overnight in the dark at room temperature. Excess dansyl chloride was removed by addition of $100 \mu \mathrm{L}$-proline $(1.3 \mathrm{M}$ in water) followed by a further $30 \mathrm{~min}$ of incubation in the dark. The contents of the tubes were then dried at $65^{\circ} \mathrm{C}$ under a stream of air, dissolved in $100 \mu l$ water, and extracted with $500 \mu$ l toluene. An aliquant $(300 \mu \mathrm{l})$ of the toluene phase was evaporated to dryness and dissolved in a final volume of 
$600 \mu 1$ methanol. A $20-\mu \mathrm{l}$ sample was applied to the column $(250 \times 4.6 \mathrm{~mm}$ i.d., Supelcosil LC-18, particle size $5 \mu \mathrm{m}$, Supelco Inc., Pasadena, CA, U.S.A.) by an autosampler, and separation of the dansyl derivatives was obtained using a linear methanol/water gradient changing from 65 to $100 \%$ methanol (Ratburn Chemicals Ltd, Walkerburn, U.K.; HPLC grade) in $23 \mathrm{~min}$ at a flow rate of $1 \mathrm{ml} / \mathrm{min}$. Elution times for the dansyl derivatives of putrescine, spermidine and spermine were about $13.4,18.9$ and $22.5 \mathrm{~min}$, respectively, whereas the internal standard eluted at $15.1 \mathrm{~min}$. External standards were run after every 7 th sample, and contained $93 \cdot 75,125,375$ and 125 pmol putrescine, internal standard, spermidine and spermine, respectively. The assay sensitivity was about 10 pmol for the various polyamines, and the within-assay coefficient of variation was $<4 \%$. The fluorescence detector used was equipped with an excitation filter of $340 \mathrm{~nm}$ and an emission filter of $460 \mathrm{~nm}$.

Statistics. Results were analysed by one-way analysis of variance after logarithmic transformation of the data.

\section{Results}

\section{Effects of lisuride on circadian variations in hormone concentrations}

As can be seen from Text-fig. 1, prolactin concentrations remained low during the whole observation period in lisuride-treated animals. Prolactin concentrations in the control animals were variable and by $12 \mathrm{~h}$ the values were not significantly different from those of lisuride-treated rats.
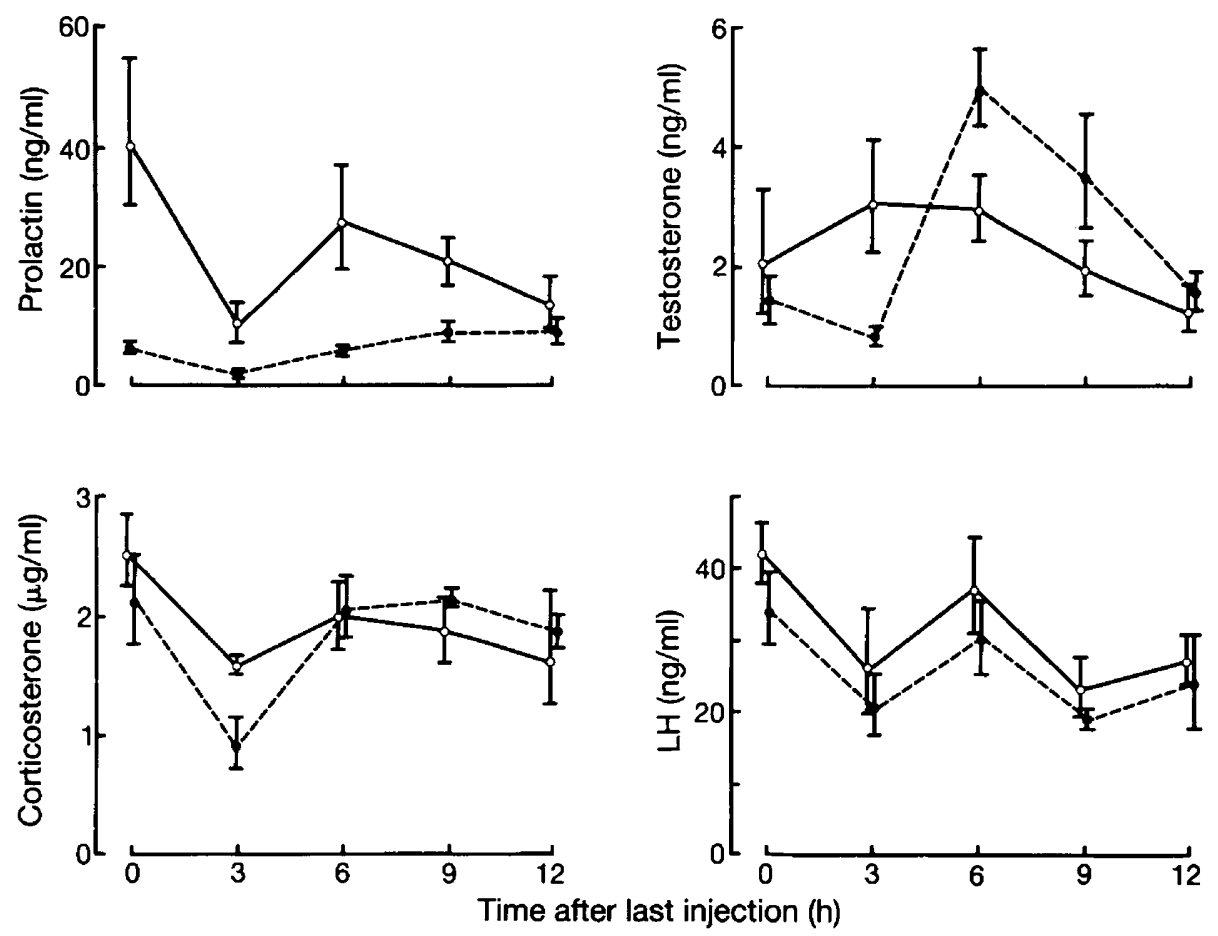

Text-fig. 1. Plasma concentrations of hormones in control and lisuride-treated intact male rats killed every $3 \mathrm{~h}$ during a $12-\mathrm{h}$ period after the last injection. Before the day of autopsy the animals had been injected s.c. twice daily with $25 \mu \mathrm{g}$ lisuride $\left(0_{---0}\right)$ or saline $\left(\mathrm{O}_{-} \mathrm{O}\right)$ for 3 days. Rats killed at time zero did not receive the final injection. Vertical bars represent geometric means \pm s.e. for 5 rats/group. 

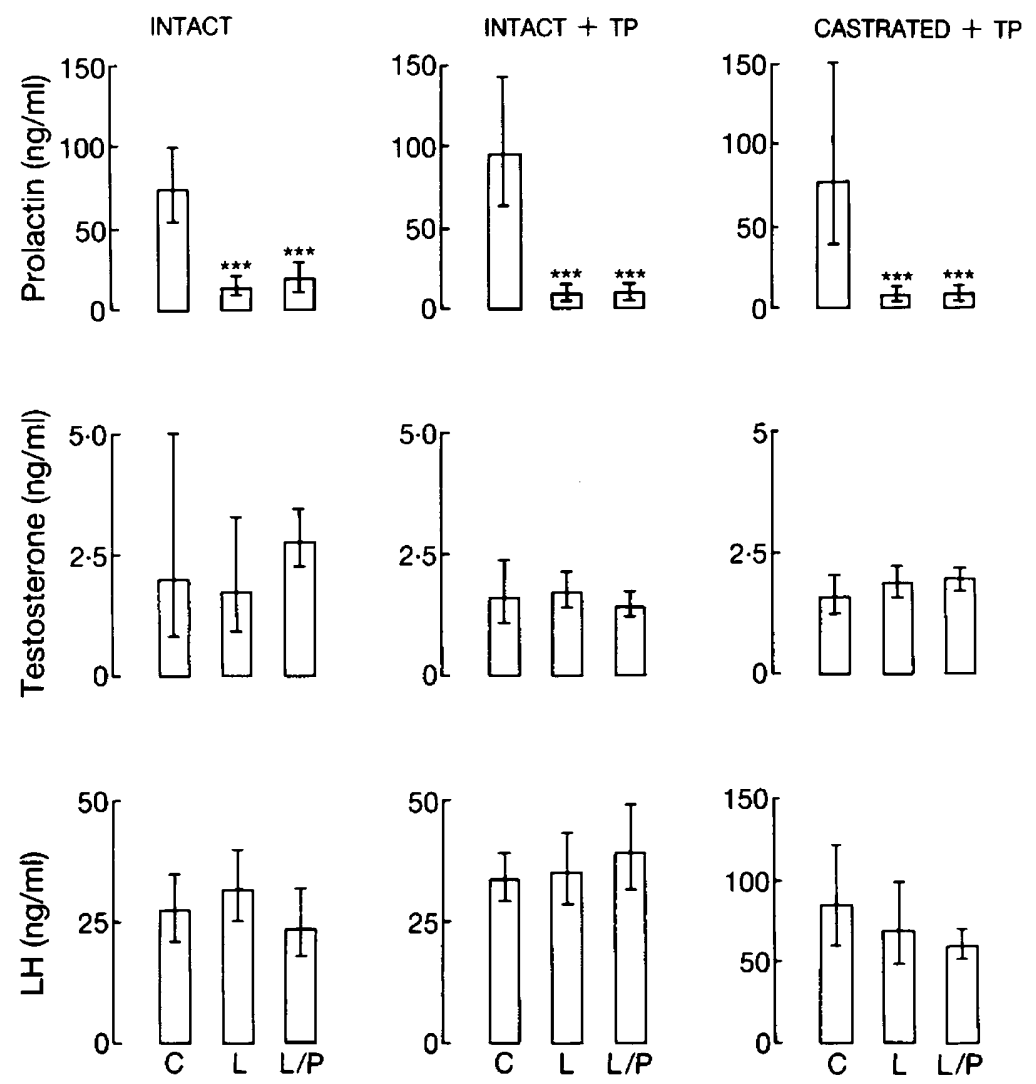

Text-fig. 2. Plasma concentrations of prolactin, testosterone and $\mathrm{LH}$ after 7 days of lisuride treatment $(25 \mu \mathrm{g}$ s.c. twice daily) of intact, intact-androgenized ( $100 \mu \mathrm{g}$ testosterone propionate daily) and castrated-androgenized rats. The results are obtained from three separate studies. Rats in one of the lisuride-treated groups $(\mathrm{L} / \mathrm{P})$ received a single s.c. injection of ovine prolactin $(75 \mu \mathrm{g})$ concomitant with the last lisuride injection $12 \mathrm{~h}$ before autopsy. Control animals (C) received saline. Vertical bars represent $95 \%$ confidence limits of geometric means $(N=8)$. ***Values significantly different from those of control rats, $P<0.001$.

LH and corticosterone concentrations were not affected by lisuride treatment. Testosterone values exhibited an apparent bimodal response to the drug, showing an initial reduction (to $28 \%$ of control value, $P<0.02$ ) $3 \mathrm{~h}$ after injection and an elevation (to $169 \%$ of control value, $P<0.05$ ) after a further $3 \mathrm{~h}$, followed by a gradual normalization to control levels over the next $6 \mathrm{~h}$.

\section{Effects of lisuride and prolactin on the prostate}

Plasma prolactin concentration was markedly reduced in lisuride-treated rats, an effect also observed in animals that had received a single prolactin injection $12 \mathrm{~h}$ before autopsy in addition to lisuride treatment (Text-fig. 2), which partly reflects the specificity of the rat prolactin assay and partly the rapid clearance of this hormone from the circulation. No significant deviation from control levels was observed with regard to plasma testosterone or $\mathrm{LH}$, although there was a tendency in intact rats for testosterone to be elevated $12 \mathrm{~h}$ after the prolactin injection. In the intact animals testicular weight was significantly reduced by lisuride treatment $(P<0.01)$, an effect which was not 
Table 1. Testicular weight, lateral lobe zinc and coagulating gland fructose concentrations in control (C), lisuride-treated (L) and lisuride-treated rats exposed to a single dose of prolactin $12 \mathrm{~h}$ before autopsy $(\mathbf{L} / \mathbf{P})$

\begin{tabular}{ccccc}
\hline & $\begin{array}{c}\text { Treatment } \\
\text { group }\end{array}$ & $\begin{array}{c}\text { Intact } \\
\text { rats }\end{array}$ & $\begin{array}{c}\text { Intact- } \\
\text { androgenized } \\
\text { rats } \dagger\end{array}$ & $\begin{array}{c}\text { Castrated- } \\
\text { androgenized } \\
\text { rats } \dagger\end{array}$ \\
\hline $\begin{array}{c}\text { Testicular weight } \\
(\mathrm{g})\end{array}$ & $\mathrm{C}$ & $4 \cdot 1(4 \cdot 0-4 \cdot 3)$ & $4 \cdot 0(3 \cdot 6-4 \cdot 4)$ & \\
& $\mathrm{L}$ & $3 \cdot 7(3 \cdot 6-3 \cdot 9)^{* * *}$ & $4 \cdot 0(3 \cdot 9-4 \cdot 1)$ & \\
Lateral lobe & $\mathrm{L} / \mathrm{P}$ & $3 \cdot 8(3 \cdot 7-4 \cdot 0)^{* * *}$ & $4 \cdot 0(3 \cdot 8-4 \cdot 3)$ & \\
$\quad$ zinc & $\mathrm{C}$ & $185(164-210)$ & $163(109-244)$ & $148(121-181)$ \\
$(\mu \mathrm{g} / \mathrm{g}$ wet wt) & $\mathrm{L}$ & $146(117-183)^{*}$ & $96(58-142)^{* *}$ & $123(103-147)$ \\
Coagulating gland & $\mathrm{L} / \mathrm{P}$ & $122(77-191)$ & $114(83-157)$ & $99(81-121)^{* * *}$ \\
fructose & $\mathrm{C}$ & $34 \cdot 7(33-36)$ & $43 \cdot 6(39-49)$ & \\
$(\mu \mathrm{g} / \mathrm{mg}$ protein) & $\mathrm{L}$ & $34 \cdot 9(30-41)$ & $41 \cdot 2(34-50)$ & Not determined \\
\hline
\end{tabular}

Values are geometric means (with $95 \%$ confidence limits) for 8 rats/group.

${ }^{*} P<0.05 ;{ }^{* *} P<0.02 ;{ }^{* *} P<0.01$ for differences from control levels.

$\dagger 100 \mu \mathrm{g}$ testosterone propionate i.m. daily during the treatment period.
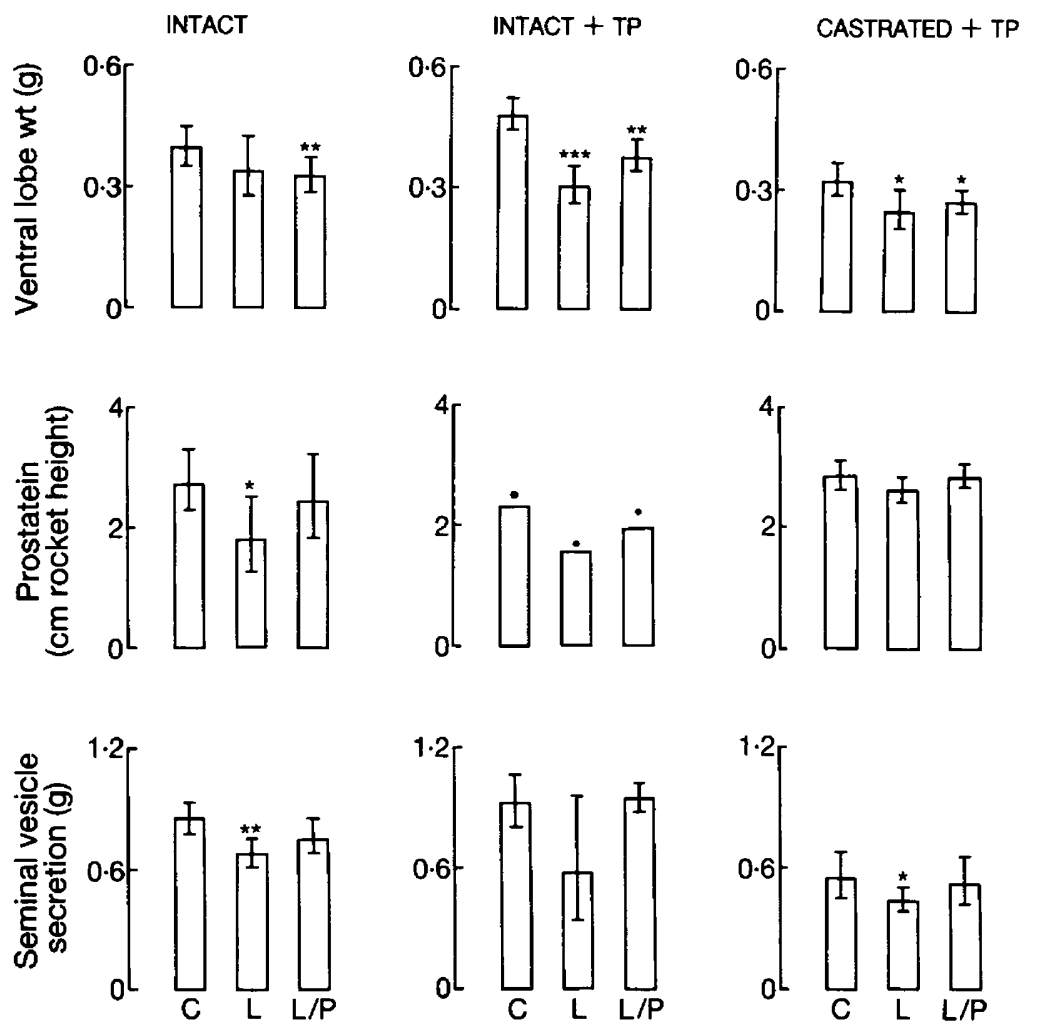

Text-fig. 3. Ventral lobe prostate weight, ventral lobe prostatein concentration and seminal vesicle secretion in control (C), lisuride-treated (L) and lisuride-treated rats exposed to a single dose of ovine prolactin $(\mathbf{L} / \mathbf{P})$. Prostatein determinations in intact-androgenized rats were carried out on pools of tissue (s.d. of triplicate measurements are indicated). Vertical bars represent $95 \%$ confidence limits of geometric means $(\mathrm{N}=8)$. Values significantly different from control levels; ${ }^{*} P<0.05 ;{ }^{* *} P<0.01 ;{ }^{* *} P<0.001$. 

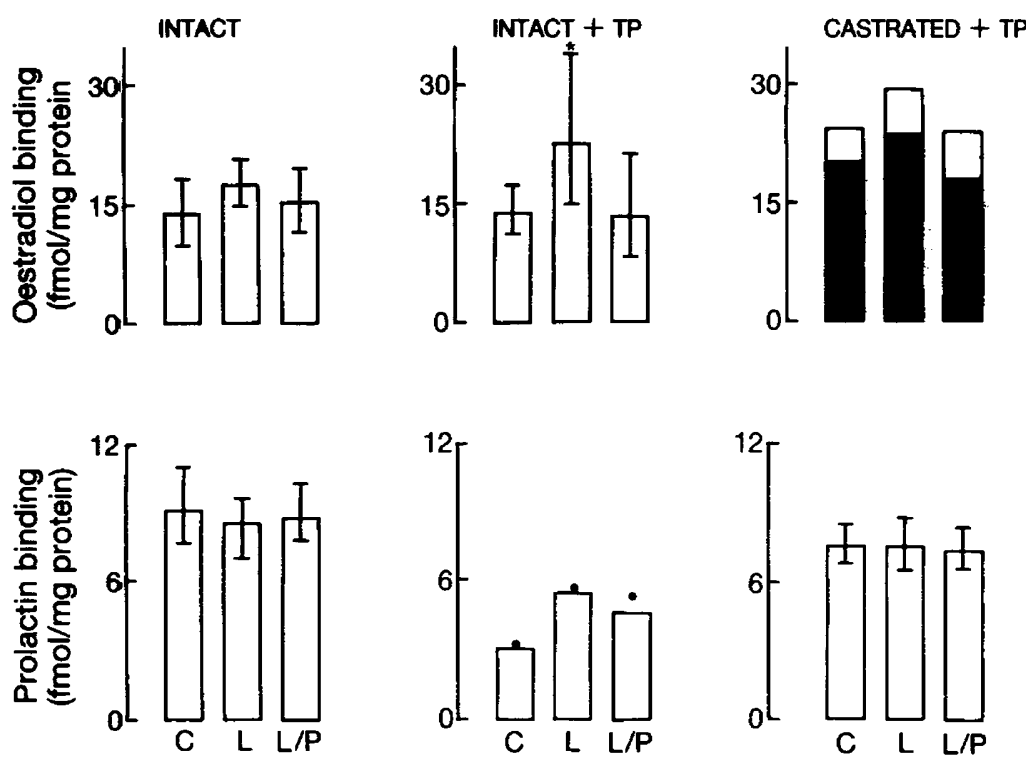

Text-fig. 4. Binding of oestradiol and prolactin in the cytosols and membranes, respectively, in control (C), lisuride-treated (L) and lisuride-treated rats exposed to a single dose of ovine prolactin $(\mathrm{L} / \mathrm{P})$. Data on oestradiol binding in androgenized-castrated rats is derived from Scatchard analysis on pooled tissue: the shaded area of these columns represents the lower affinity component (see Text-fig. 5). Measurement of prolactin binding in intact-androgenized rats was also carried out on pooled membranes (s.d. of triplicate determinations are indicated). Vertical bars represent $95 \%$ confidence limits of geometric means $(\mathrm{N}=8) .{ }^{*} P<0.05$ compared with control level.

reversed within $12 \mathrm{~h}$ of a single prolactin injection $(P<0.01$; Table 1$)$. No effect on testicular weight was observed in intact androgenized rats. Table 1 also shows the concentration of zinc in the lateral lobes and fructose in the coagulating glands of these animals. The zinc concentration was reduced by lisuride treatment, but showed no indication of reversal towards control levels within $12 \mathrm{~h}$ of exposure to prolactin. Coagulating gland fructose was not altered by lisuride or prolactin.

The effects of 7 days of lisuride treatment and lisuride combined with a single injection of prolactin on ventral prostate weight, ventral prostate content of prostatein and seminal vesicle secretion are shown in Text-fig. 3. Lisuride significantly reduced prostate weight in intact-androgenized $(P<0.001)$ and castrated-androgenized $(P<0.05)$ rats. A single dose of prolactin at the end of the treatment period did not reverse these weights to normal, at least within $12 \mathrm{~h}$. The greatest

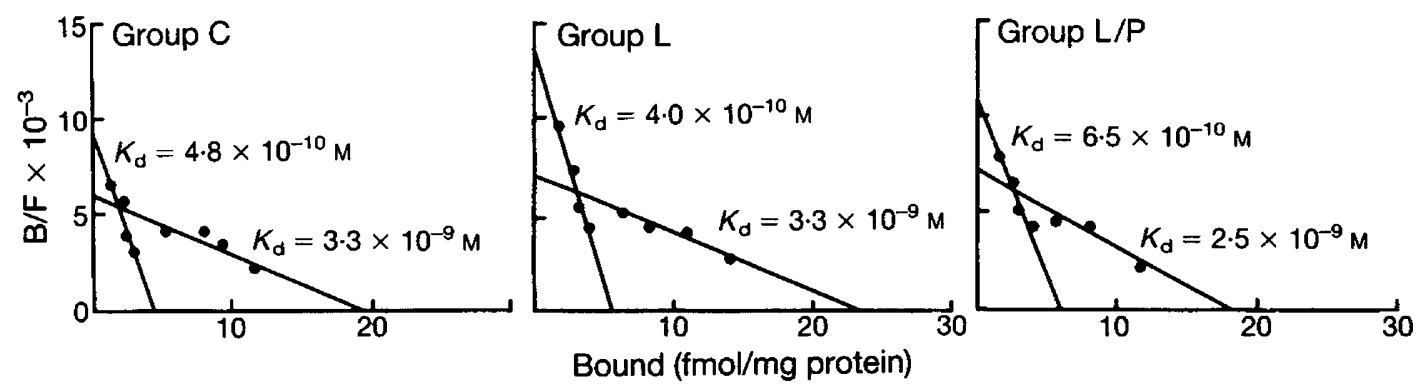

Text-fig. 5. Scatchard plots of specific oestradiol binding to pooled cytosols from control (C), lisuride-treated (L) and lisuride-treated rats exposed to a single dose of prolactin $(\mathrm{L} / \mathrm{P})$. 
inhibitory effect of the drug was seen in intact-androgenized rats, in which the mean weight of the prostate in lisuride-treated animals was reduced to $64 \%$ of values in controls.

Prostatein was also affected to some degree by prolactin withdrawal, being reduced to 65,68 and $93 \%$ after lisuride treatment in intact, intact-androgenized and castrated-androgenized animals, respectively. In intact animals, prolactin increased the concentration of this protein to a level which was not significantly different from control (Text-fig. 3).

The amount of secretion in the seminal vesicles in lisuride-treated rats was reduced to $80 \%$ $(P<0.01)$ in intact, 63\% (not significant) in intact-androgenized and $81 \%(P<0.05)$ in castrated-androgenized animals as compared to their respective control groups (Text-fig. 3). In all three experiments prolactin reversed this change when administered $12 \mathrm{~h}$ before autopsy.

The binding of oestradiol in ventral prostate cytosol was elevated significantly by lisuride treatment $(P<0.05)$ only in intact-androgenized rats (Text-fig. 4$)$. In the experiment with castratedandrogenized rats, Scatchard analysis of the binding was performed, which indicated that the effect
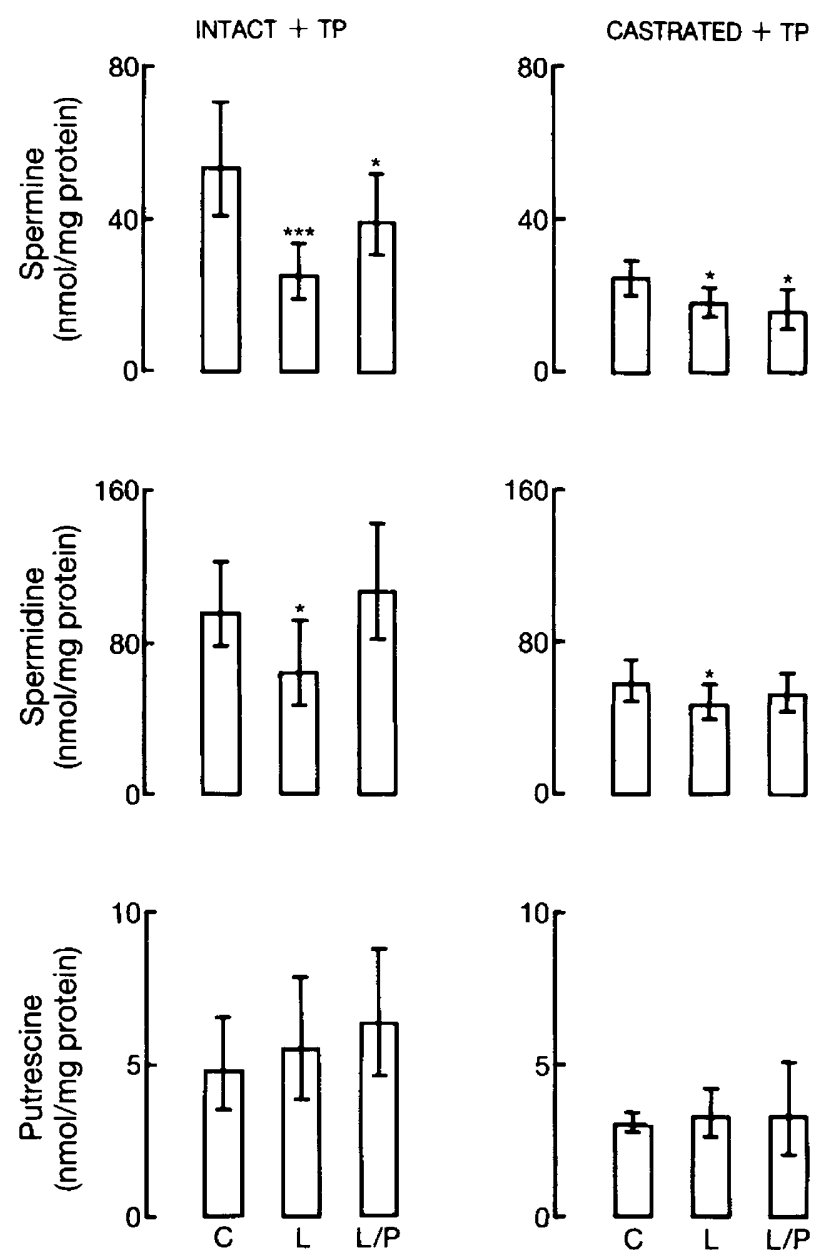

Text-fig. 6. Ventral prostate spermine, spermidine and putrescine concentrations in control (C), lisuride-treated (L) and lisuride-treated rats exposed to a single dose of ovine prolactin $(\mathrm{L} / \mathrm{P})$. Data are obtained from two separate experiments using intact-androgenized (100 $\mu \mathrm{g}$ testosterone propionate, i.m. daily) or castrated-androgenized animals. Vertical bars represent $95 \%$ confidence limits of geometric means $(\mathrm{N}=8)$. ${ }^{*} P<0.05 ;{ }^{* * *} P<0.001$ compared with control levels. 
involved two relatively high-affinity components, with apparent $K_{\mathrm{d}}$ values of $5 \times 10^{-10} \mathrm{M}$ and $3.4 \times 10^{-9} \mathrm{M}$, respectively (Text-fig. 5). Prolactin administration reduced oestrogen binding $(P<0.05)$ in intact-androgenized animals.

The binding of prolactin to ventral prostate membranes did not exhibit a consistent response to lisuride or prolactin (Text-fig. 4).

Cytosolic putrescine concentration was unaffected by treatment with lisuride or prolactin, but spermine was reduced to $47 \%(P<0.001)$ and $74 \%(P<0.02)$ of the values in intactandrogenized and castrated-androgenized rats, respectively (Text-fig. 6). Corresponding values for spermidine were $67 \%(P<0.05)$ and $81 \%(P<0.05)$. By $12 \mathrm{~h}$ after a single prolactin injection, spermidine levels were restored or almost restored to control values, while those of spermine responded to a lesser degree.

\section{Discussion}

In agreement with numerous reports the present study provides clear evidence that prolactin is necessary to maintain the integrity of at least some aspects of accessory sex gland function in the male rat. The degree to which prolactin withdrawal and addition influenced certain of the prostatic characteristics differed between the different experiments and may be related to differences in the concentrations of circulating androgen. The major stimulus to prostatic growth and function is testosterone, and the extent to which the prostatic cells are primed by this steroid may determine the degree of response to prolactin deficiency or excess. This interaction between androgen and prolactin may be one of the reasons why differences attained statistical significance in some experiments and not in others. However, it should be emphasized that the directions of these changes were the same in all three studies and therefore further evidence of a treatment effect.

Ventral prostate weights of control animals differed between the three studies, indicating that the degree of androgenization of the animals may have differed in the three experiments, despite the fact that this was not evident from the circulating testosterone concentrations. Indeed, the effects of prolactin were less obvious in the third study in which the lowest control prostate weights were recorded, suggesting that a particular threshold of androgenization may be necessary before the effects of prolactin withdrawal and addition are clearly manifested.

Another consideration in the interpretation of these studies is the efficacy with which lisuride removes prolactin from the peripheral circulation. All 4 studies indicated that the dose of lisuride used could not completely remove prolactin from the circulation. However, it is impossible to gauge how effective this basal level of prolactin secretion is in maintaining prostatic function, thereby reducing the difference from control levels.

Prolactin exerted relatively rapid effects on certain aspects of prostatic and vesicular function in prolactin-deficient rats, whereas other values appeared to require longer periods of exposure before returning to control levels. The reductions in the volume of vesicular secretion and the ventral prostate concentrations of prostatein and spermidine after lisuride treatment were all reversed towards control levels $12 \mathrm{~h}$ after a single prolactin injection. Several aspects of prostatic and seminal vesicle function were influenced by this hormone, whereas others (ventral lobe prolactin binding and coagulating gland fructose) were unaffected. Most of the characteristics examined were stimulated by prolactin but at least one, cytosolic oestrogen binding, appeared to be inversely related to circulating prolactin concentrations. Since lisuride administration was continued in the rats receiving prolactin, these rapid effects can be attributed to alterations in circulating prolactin and not to direct effects of the drug on the glands.

One of the potential complications in studies on prolactin withdrawal on androgen target organs is that some of the effects that are observed may be a result of the effect of prolactin on Leydig cell function. Several authors have shown that prolactin withdrawal has marked effects on the steroidogenic response of rat Leydig cells to LH (Bex \& Bartke, 1977; Purvis et al., 1979). 
Indeed, in intact rats there was a tendency for blood testosterone to be reduced in lisuride-treated animals and stimulated $12 \mathrm{~h}$ after prolactin injection. Testicular weights in this first study were also reduced in prolactin-deficient animals to a small but significant degree, indicating possible direct effects at the Leydig cell level.

The separate study on the effects of lisuride on various circulating hormones in intact rats indicated that the androgen concentrations observed in the treated animals at the time of autopsy altered markedly in relation to the time of the last injection. Such findings suggest that caution should be exercised in interpreting drug effects on the pituitary-testicular axis when they are based on single hormone determinations at a particular time after drug administration. Indeed, in the intact rats of this study, lisuride exerted both stimulatory and inhibitory effects on androgen values depending on the time of autopsy. For this reason in two of the subsequent studies plasma testosterone was kept artificially stable by exogenous administration to rule out hidden effects of prolactin withdrawal on the testis which could confound interpretation of the prostatic effects.

The fact that the majority of effects observed in intact rats were confirmed in these androgensubstituted animals indicated that an androgen deficiency could not explain the drug's influence on the prostate. Moreover, there was no indication that adrenal function was disturbed by lisuride, as judged by the levels of circulating corticosterone in the treated animals, reducing the possibility that these prostatic effects could be explained by androgens from an adrenal source.

The fact that spermidine and spermine and not their diamine precursor putrescine were lowered by lisuride treatment of androgen-treated rats indicated a relatively greater effect on the enzyme $S$-adenosyl-L-methionine-decarboxylase than on ornithine decarboxylase. These enzymes are recognized as rate-limiting in the polyamine biosynthetic pathway (Pegg, Lockwood \& WilliamsAshman, 1970). Prolactin has been reported to influence the polyamine values in a variety of tissues (Richards, 1975), and these amines are involved in the regulation of growth and protein synthesis in several organs including the prostate (Heston, Kadmon, Lazan \& Fair, 1982; Herr \& Kleinert, 1984), where they also represent major secretory components (Mann \& Lutwak-Mann, 1981).

An observation which is more difficult to explain is the apparent interaction between prolactin and the binding of oestradiol to components in the prostatic cytosol. Scatchard analysis revealed that the hormone appeared to exert effects on one of the two binding components which can be demonstrated in the cytosol, the relatively lower-affinity high-capacity component which appears to be distinct from the classical oestrogen receptor (Purvis et al., 1985). Because the analysis was carried out on pools of tissue it was not possible in this study to obtain statistical proof for the apparent effect on the low affinity component. The mechanism of this interaction is, however, currently being investigated. The apparent lack of effects of prolactin withdrawal and addition on the levels of its own membrane receptor supports previous observations indicating that this receptor is relatively resistant to up or down regulation by prolactin in this gland (Kledzik, Marshall, Campbell, Gelato \& Meites, 1976; Barkey, Shani \& Barzilai, 1979).

Numerous reports have indicated that the lateral lobes of the rat are particularly sensitive to prolactin (Grayhack \& Lebowitz, 1967; Moger \& Geschwind, 1972; Prins \& Lee, 1982). In the present report the zinc content of the lateral lobe was used as a functional indicator for this tissue and, in apparent confirmation of these earlier findings, prolactin withdrawal was associated with a decrease in the tissue concentration of the metal. However, no evidence was obtained indicating that prolactin treatment could reverse these changes, at least within $12 \mathrm{~h}$ of injection. Such results may indicate that the biochemical mechanisms underlying zinc uptake may be only slowly induced or that the rate of uptake of this metal ion when returned to normal is of such a low order that it takes time for differences to be manifest.

The present study confirms a role for prolactin in prostatic function in the rat, but also extends previous observations by demonstrating a complex interaction of the hormone with several aspects of prostatic biochemistry, including the levels of polyamines, prostatein and oestrogen binding. Rui, Gordeladze, Gautvik \& Purvis (1984) have presented indirect evidence that prolactin may modify the local levels of prostaglandin E-1 in prostatic tissue, and current views support the 
idea that this may mediate at least some of the effects of prolactin on target organs such as the mammary gland (Horrobin, 1979).

We thank Dr O. Lea, Haukeland Hospital, Bergen, for the gift of prostatein antiserum, Dr K. Eliassen and Dineke Grønnseth at the Veterinary College, University of Oslo, for help and guidance in the establishment of the polyamine assay; and Inger Brekke and Lise Mørkås for skilful technical help. The study was supported by Norsk Forening til Kreftens Bekjempelse and Landsforeningen mot Kreft. H.R. is in receipt of a NAVF scholarship.

\section{References}

Aragona, C. \& Friesen, H.G. (1975) Specific prolactin binding sites in the prostate and testis of rats. Endocrinology $97,677-684$.

Baker, H.W.G., Worgut, T.J., Santen, R.J., Jefferson, L.S. \& Bardin, C.W. (1977) Effect of prolactin on nuclear androgens in perfused male accessory sex organs. In The Testis in Normal and Infertile Men, pp. 379-385. Eds P. Troen \& H. R. Nankin. Raven Press, New York.

Barkey, R.J., Shani, J. \& Barzilai, D. (1979) Regulation of prolactin binding sites in the seminal vesicle, prostate gland, testis and liver of intact and castrated adult rats: effects of administration of testosterone, 2-bromo-a-ergocryptine and fluphenazine. J. Endocr. 81, 11-18.

Bartke, A. (1980) Role of prolactin in reproduction in male mammals. Fedn Proc. Fedn Am. Socs exp. Biol. $39,2577-2581$.

Bartke, A. \& Lloyd, C.W. (1970) The influence of pituitary homografts on the weight of sex accessories in castrated male mice and rats and on mating behaviour in male mice. J. Endocr. 46, 313-320.

Bex, F.J. \& Bartke, A. (1977) Testicular LH binding in the hamster: modification by photoperiod and prolactin. Endocrinology 100, 1223-1226.

Charreau, E.H., Attramadal, A., Torjesen, P.A., Purvis, K., Calandra, R. \& Hansson, V. (1977) Prolactin binding in rat testis: specific receptors in interstitial cells. Molec. cell. Endocr. 6, 303-307.

Flückiger, E. (1976) The pharmacology of bromocriptine. In Pharmacological and Clinical Aspects of Bromocriptine (Parlodel), pp. 12-26. Eds R. I. S. Bayliss, P. Turner \& W. P. Maclay, MCS Consultants, Tunbridge Wells.

Ghosh, S.P., Chatterjee, T.K. \& Ghosh, J.J. (1983) Synergistic role of prolactin in the regulation of acid phosphatase activity and isoenzyme pattern in the accessory sex organs of adult male rats. J. Reprod. Fert. 67, 235-238.

Ginsburg, M., Jung-Testas, I. \& Baulieu, E.E. (1980) Specific high affinity oestradiol binding in rat ventral prostate. J. Endocr. 87, 285-292.

Gräf, K-J., Neumann, F. \& Horowski, R. (1976) Effect of the ergot derivative lisuride hydrogen maleate on serum prolactin concentrations in female rats. Endocrinology 98, 598-605.

Grayhack, J.T. (1963) Pituitary factors influencing growth of the prostate. Natl Cancer Inst. Monogr. 12, 189-199.

Grayhack, J.T. \& Lebowitz, J.M. (1967) Effect of pro- lactin on citric acid of lateral lobe of prostate of Sprague-Dawley rats. Invest. Urol. 5, 87-94.

Hanlin, M.L. \& Yount, A.P. (1975) Prolactin binding in the rat ventral prostate. Endocrine Res. Commun. 2, 489-502.

Harper, M.E., Danutra, V., Chandler, J.A. \& Griffiths, $K$. (1976) The effect of 2-bromo-a-ergocryptine (CB 154) administration on the hormone levels, organ weights, prostatic morphology and zinc concentrations in the male rat. Acta endocr., Copenh. 83, 211-224.

Haug, E. \& Gautvik, K.M. (1976) Effects of sex steroids on prolactin secreting rat pituitary cells in culture. Endocrinology 99, 1482-1489.

Herr, H.W. \& Kleinert, E.L. (1984) Antigrowth effect of polyamine biosynthesis inhibitors on the Dunning $\mathbf{R}$ 3327-G prostatic tumor. The Prostate 5, 439-444.

Heston, W.D.W., Kadmon, D., Lazan, D.W. \& Fair, W.R. (1982) Copenhagen rat prostatic tumor ornithine decarboxylase activity (ODC) and the effect of the ODC inhibitor alpha-difluorometyl-ornithine. The Prostate 3, 383-389.

Horrobin, D.F. (1979) Cellular basis of prolactin action: involvement of cyclic nucleotides, polyamines, prostaglandins, steroids, thyroid hormones, $\mathrm{Na} / \mathrm{K}$ ATPases and calcium: relevance to breast cancer and the menstrual cycle. Med. Hypotheses 5, 599-620.

Jung-Testas, I., Groyer, M.-T., Bruner-Lorand, J., Hechter, O., Baulieu, E.E. \& Robel, P. (1981) Androgen and oestrogen receptors in rat ventral prostate, epithelium and stroma. Endocrinology 109, 1287-1289.

Kledzik, G.S., Marshall, S., Campbell, G.A., Gelato, M. \& Meites, J. (1976) Effects of castration, testosterone, estradiol, and prolactin on specific prolactinbinding activity in ventral prostate of male rats. Endocrinology 98, 373-379.

Lea, O.A., Petrusz, P. \& French, F.S. (1979) Prostatein: a major secretory protein of the rat ventral prostate. $J$. biol. Chem. 254, 6196-6202.

Mann, T. \& Lutwak-Mann, C. (1981) Male Reproductive Function and Semen. Springer-Verlag, Berlin.

McKeehan, W.L., Adams, P.S. \& Rosser, M.P. (1984) Direct mitogenic effects of insulin, epidermal growth factor, glucocorticoid, cholera toxin, unknown pituitary factors and possibly prolactin, but not androgen, on normal rat prostate epithelial cells in serum-free, primary cell culture. Cancer Res. 44, 1998-2010.

Moger, W.H. \& Geschwind, I.I. (1972) The action of prolactin on the sex accessory sex gland of the male rat. Proc. Soc. exp. Biol. Med. 141, 1017-1021. 
Negro-Vilar, A., Saad, W.A. \& MeCann, S.M. (1977) Evidence for a role of prolactin in prostate and seminal vesicle growth in immature male rats. Endocrinology 100, 729-737.

Pegg, A.E., Lockwood, D.H. \& Williams-Ashman, H.G. (1970) Concentrations of putrescine and polyamines and their enzymic synthesis during androgen-induced prostatic growth. Biochem. J. 177, 17-31.

Prins, G.S. \& Lee, C. (1982) Influence of prolactinproducing pituitary grafts on the in vivo uptake, distribution, and disappearance of ${ }^{3} \mathrm{H}$-testosterone and ${ }^{3} \mathrm{H}$-dihydrotestosterone by the rat prostate lobes. Endocrinology 100, 920-925.

Prins, G.S. \& Lee, C. (1983) Biphasic response of the rat lateral prostate to increasing levels of serum prolactin. Biol. Reprod. 29, 938-945.

Purvis, K., Illius, A.W. \& Haynes, N.B. (1974) Plasma testosterone concentrations in the rat. J. Endocr. 61, 241-253.

Purvis, K., Haug, E., Clausen, O.P.F., Naess, O. \& Hansson, V. (1977) Endocrine status of the testicular feminized male (tfm) rat. Molec. cell. Endocr. 8, 73-80.

Purvis, K., Calandra, R. \& Hansson, V. (1977) Adrenal secretion and plasma CBG levels in the immature male rat: effects of $5 \alpha$-reduced androgens and antiandrogens. J. Steroid Biochem. 8, 1121-1124.

Purvis, K., Clausen, O.P.F., Olsen, A., Haug, E. \& Hansson, V. (1979) Prolactin and Leydig cell responsiveness to LH/hCG in the rat. Archs Androl. 3, 219-230.

Purvis, K., Merkås, L., Rui, H. \& Attramadal, A. (1985) Oestrogen receptors in stromal and epithelial fractions of the rat ventral prostate. Archs Androl. in press.

Richards, J.F. (1975) Ornithine decarboxylase activity in tissues of prolactin-treated rats. Biochem. Biophys. Res. Commun. 63, 292-299.
Ricterich, R. (1969) Theory and practise. In Clinical Chemistry, 2nd edn, p. 477. Academic Press, New York.

Rui, H., Gordeladze, J.O., Gautvik, K.M. \& Purvis, K. (1984) Prolactin desensitizes the prostaglandin $E_{1}$ dependent adenylyl cyclase in the rat prostate. Molec. cell. Endocr. 38, 53-60.

Seiler, N. \& Knödgen, B. (1978) Determination of di- and polyamines by high performance liquid chromatographic separation of their 5-dimethylaminonaphtalene-L-sulphonyl derivatives. $J$. Chromatogr. 145, 29-39.

Slaunwhite, W.R. \& Sharma, M. (1977) Effects of hypophysectomy and prolactin replacement therapy on prostatic response to androgen in orchidectomized rats. Biol. Reprod. 17, 489-492.

Thomas, J.A. \& Manandhar, M. (1975) Effects of prolactin and/or testosterone on nucleic acid levels in prostate glands of normal and castrated rats. $J$. Endocr. 65, 149-150.

Thomas, J.A., Manandhar, M.S., Keenan, E.J., Edwards, W.D. \& Klase, P.A. (1976) Effects of prolactin and dihydrotestosterone upon the rat prostate gland. Urol. int. 31, 265-271.

Thompson, S.A., Johnson, M.P. \& Brooks, C.L. (1982) Biochemical and immunohistochemical characterization of prolactin binding in rat ventral, lateral and dorsal prostate lobes. The Prostate 3, 45-58.

Walvoord, D.J., Resnick, M.I. \& Grayhack, J.T. (1976) Effect of testosterone, dihydrotestosterone, estradiol, and prolactin on the weight and citric acid content of the lateral lobe of the rat prostate. Invest. Urol. 14, 60-65.

Weinstein, E. \& Rosoff, B. (1972) Effect of prolactin on prostatic weight and zinc- 65 uptake in castrated rats. Fedn Proc. Fedn Am. Socs exp. Biol. 31, 275, Abstr.

Received 28 December 1984 